\title{
Regional cerebral oxygen saturation is a useful predictive factor of postoperative cerebral infarction for acute aortic dissection involving the aortic arch
}

\author{
Kurashiki Central Hospital
}

Kazuhiko Kosobe , Kosaku Toyota , Akiko Tomita , Shigeki Yamashita

\section{【Background】}

Cerebral malperfusion is a serious complication in the anesthetic management of patients with acute type $A$ dissection of aorta (DA). Especially, cerebral perfusion can be restricted if the dissected area involves the aortic arch and the cervical branches.

Previous studies have reported that operation time and an intraoperative depression of regional cerebral oxygen saturation $\left(\mathrm{rSO}_{2}\right)$ can be predictive factors for detecting cerebral malperfusion in patients with DA. However independent risk factors other than $\mathrm{rSO}_{2}$ for cerebral malperfusion in patients with DA involving the aortic arch are not clear.

\section{【Aim】}

This retrospective observational study was aimed to investigate the factors which are correlated with postoperative cerebral infarction $(\mathrm{Cl})$ in patients with DA involving the aortic arch.

\section{【Materials and Methods】}

The study was approved by the Institutional Ethics Committee of Kurashiki Central Hospital (October,2016).

Subjects: Patients who underwent urgent aortic surgery involving arch dissection.

Study duration: December 1st 2010 - October 30st 2016.

Measurement: Operation (Op) time, cardiopulmonary bypass time, aortic clamping time, selective cerebral perfusion time, circulatory arrest (CA) time, amount of bleeding, amount of transfusion, and $\mathrm{rSO}_{2}$ values. Statistical analysis: Non-paired t-test, logistic regression, and receiver operating characteristic (ROC) curve analysis.

A $p$ value of less than 0.05 was considered as significant.

\section{【Results】}

Independent risk factors for $\mathrm{Cl}$

\begin{tabular}{|c|c|c|c|}
\hline & OR & $95 \% \mathrm{Cl}$ & P-value \\
\hline Op time(min) & 1.010 & $1.00-1.02$ & 0.00251 \\
\hline CA time(min) & 0.985 & $0.934-1.04$ & 0.963 \\
\hline Bleeding(ml) & 1.000 & $1.000-1.00$ & 0.535 \\
\hline Transfusion(ml) & 1.000 & $1.000-1.00$ & 0.699 \\
\hline $\mathrm{rSO}_{2}<50 \%(\mathrm{~min})$ & 1.010 & $1.000-1.02$ & 0.00738 \\
\hline
\end{tabular}

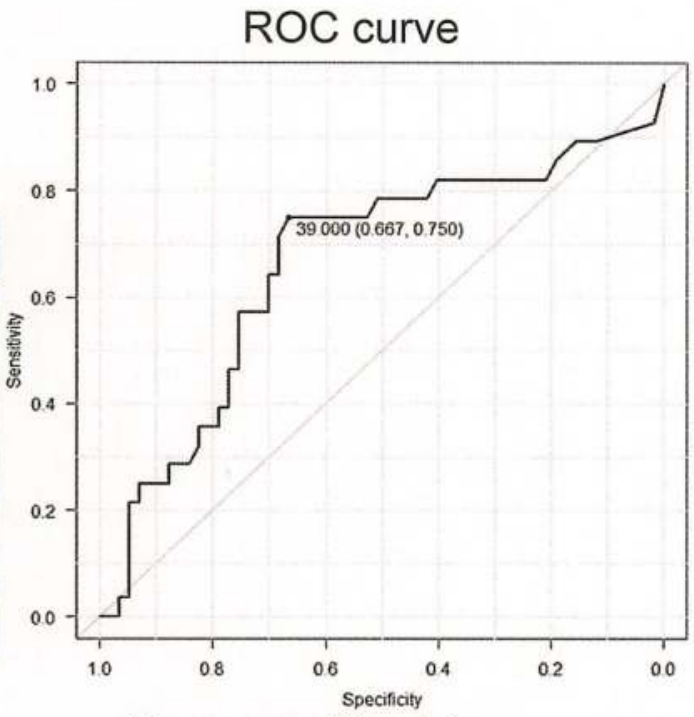

Independent risk factors for $\mathrm{Cl}$ : operation time $(\mathrm{OR}=1.01$, $95 \% \mathrm{Cl} 1.00-1.02)$, and time duration of rSO2 below $50 \%$ ( OR=1.01, 95\% Cl 1.00-1.02).

ROC curve analysis: rSO2 depression below $50 \%$ of longer than 39 minutes was a significant independent predictor of postoperative $\mathrm{Cl}$ (Sensitivity: $75 \%$ Specificity: $67 \%, \mathrm{P}=0.0003$ ).

\section{【Conclusion】}

These results indicate that prolonged depression in $\mathrm{rSO}_{2}$ and operation time are useful predictors for postoperative $\mathrm{Cl}$ in patients with DA involving the aortic arch.

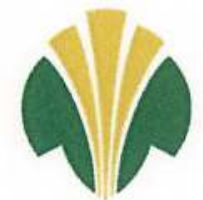

\begin{tabular}{|l|l|l|}
\hline & $\begin{array}{l}\mathrm{Cl} \text { group } \\
(\mathrm{n}=28)\end{array}$ & $\begin{array}{l}\text { Non }-\mathrm{Cl} \text { group } \\
(\mathrm{n}=57)\end{array}$ \\
\hline Male/Female & $16 / 12$ & $29 / 28$ \\
\hline Age & $68.1 \pm 12.1$ & $65.8 \pm 12.9$ \\
\hline Hypertension & 23 & 51 \\
\hline Diabetes mellitus & 2 & 5 \\
\hline Dyslipidemia & 11 & 13 \\
\hline Smoking & 12 & 20 \\
\hline History of $\mathrm{Cl}$ & 10 & 4 \\
\hline Shock & 7 & 2 \\
\hline & Mean $\pm \mathrm{SD}$ & \\
\hline
\end{tabular}

